\title{
The Effect of Photobiomodulation on Analgesia During Childbirth: A Controlled and Randomized Clinical Trial
}

\author{
Maria Aparecida Traverzim, PhD, ${ }^{1}$ Ana Paula Taboada Sobral, PhD, ${ }^{1}$ Kristianne Porta Santos Fernandes, PhD, \\ Daniela de Fátima Teixeira Silva, PhD, ${ }^{1}$ Christiane Pavani, PhD, ${ }^{1}$ Raquel Agnelli Mesquita-Ferrari, PhD, \\ Anna Carolina Ratto Tempestini Horliana, PhD, Andréa Oliver Gomes, PhD, ${ }^{1}$ \\ Sandra Kalil Bussadori, PhD, and Lara Jansiski Motta, PhD ${ }^{1}$
}

\begin{abstract}
Background: Pain during labor can be a barrier when choosing vaginal delivery. In an attempt to relief pain during labor, several pharmacological and nonpharmacological methods are proposed.

Objective: To assess the effect of light-emitting diode (LED) photobiomodulation on analgesia during labor. Methods: A clinical trial was conducted with 29 women who were divided into two groups: G1 (experimental group-LED) and G2 (control group-hot shower). In the experimental group, an LED plate with red and infrared merged [red $660 \pm 20 \mathrm{~nm}, 5 \mathrm{~mW} / \mathrm{cm}^{2}, 3 \mathrm{~J}$ per LED $(108 \mathrm{~J})$ and infrared $850 \pm 20 \mathrm{~nm}, 5 \mathrm{~mW} / \mathrm{cm}^{2}, 3 \mathrm{~J}$ per LED $(108 \mathrm{~J})$, total energy $=216 \mathrm{~J}]$ was placed on the subjects' dorsal region, at the level of T10 to S4, for $10 \mathrm{~min}$, with the plate automatically turning off. Hot shower at controlled temperature was offered for $30 \mathrm{~min}$. To verify the effect of LED on analgesia during labor, the following variables were assessed: (1) perception of pain, (2) fetal well-being assessed by cardiotocography or intermittent auscultation of fetal heart rate, (3) Apgar score at minutes 1 and 5 after birth, and (4) labor duration.

Results: There was a statistically significant difference $(p<0.05)$ in pain reduction evidenced by a millimetric visual scale, before and after application on G1-LED (7.92 1.78). Regarding the other variables, there was no statistical difference between the groups when comparing fetal well-being, Apgar score and labor duration.

Conclusions: It is concluded that LED can be considered an alternative, since it caused pain reduction without changing other parameters during labor, compared with hot shower, a method included in hospital protocols, proving to be safe.

Clinical Trial Registration number: NCT 03496857.
\end{abstract}

Keywords: analgesia, childbirth, phototherapy, light-emitting diode

\section{Introduction}

$\mathbf{P}$ AIN DURING LABOR is one of the oldest pains reported by humankind; it is a very complex phenomenon with sensory, emotional, and perceptual components, being considered one of the most intense types of pain. ${ }^{1}$

Fear of pain during labor is probably one of the major barriers preventing pregnant women from choosing vaginal delivery, therefore, giving preference to cesarean delivery, even with all the risks inherent to this surgical procedure. These risks were observed in a systematic literature review conducted by Keag et al. in 2018, in which an association between cesarean delivery and spontaneous abortion and stillbirths was observed, in addition to increased risk of placenta previa, placental accretion, and premature detachment of placenta in later pregnancies. ${ }^{2}$ In addition to these risks, studies have also showed that children born by cesarean delivery have a higher risk of asthma, laryngitis, gastroenteritis, ulcerative colitis, and celiac disease. ${ }^{3}$

Although women recognize pain as a natural process of labor, a survey comparing the experiences of women who received care in public and private maternity hospitals

\footnotetext{
${ }^{1}$ Biophotonics Applied to Health Sciences, and ${ }^{2}$ Post Graduation Program in Rehabilitation Sciences, University Nove de Julho, São Paulo, Brazil.
} 
showed, in the interviews conducted, that fear of pain is among the main reasons why patients request a cesarean section. In addition, this survey showed that the perception of pain is different in the public and private settings. ${ }^{4}$

Private sector patients usually have analgesia methods and labor monitoring available, whereas public sector patients, in addition to not having this technology available, still have their pain increased due to routine use of oxytocin, also reporting being afraid of mistreatment by health care professionals in case they cannot control their reaction to pain due to its intensity, which causes pain perception to worsen. 4

The World Health Organization (WHO) offers a series of recommendations for adequate delivery assistance in its manual entitled WHO recommendations: intrapartum care for a positive childbirth experience, published in 2018. Although research shows a larger body of evidence to support the effectiveness of pharmacological methods, they result in a higher incidence of adverse effects. ${ }^{5}$ In an attempt to alleviate pain during labor, several pharmacological and nonpharmacological methods have been proposed. The most common nonpharmacological methods used during labor include massage, acupuncture, shower, and hypnosis. ${ }^{6-10}$

Among its effects, photobiomodulation can relieve pain, so perhaps this effect could be observed during labor and become a nonpharmacological and easy-to-use option in obstetric centers. In a review published in 2011, Kim and Calderhead observed that the main purpose of phototherapy is to control pain, which can be virtually of various etiologies. Chronic pain has historically been very difficult to control, but the effectiveness of LED (light-emitting diode) phototherapy has been well recognized. ${ }^{11}$

A study carried out by Tantawy et al. in 2018 observed reduced low back pain in patients who had their paravertebral region irradiated, demonstrating the potential central action of photobiomodulation. ${ }^{12}$ The authors point out that the mechanism behind the analgesic effect of photobiomodulation is that irradiation induces peripheral neural block, suppresses central synaptic activity, modulates neurotransmitters, reduces muscle spasm and interstitial edema, and exerts anti-inflammatory effects. In addition, light increases the production of endogenous opioid neurotransmitters, raises the pain threshold, and increases local blood circulation. ${ }^{12}$ The analgesic effects described for the lower back possibility mean that the same effects can probably be observed in pain control during labor. ${ }^{13,14}$

Therefore, the objective of this research is to assess the effect of LED photobiomodulation on analgesia during labor as an alternative nonpharmacological intervention.

\section{Methods}

\section{Research design}

This controlled and randomized clinical trial was carried out in the maternity ward of a public hospital in São Paulo (Brazil). In total, 29 parturient women participated in this study and requested some type of analgesia process during labor. Subjects were recruited on admission to the obstetric center, Perinatal Medicine Unit of the research institution, which is a reference for high-risk pregnancies in the region.

This study was carried out in accordance with the ethical guidelines in research and was approved by the Research
Ethics Committee of Conjunto Hospitalar do Mandaqui (São Paulo, Brazil) under Opinion Report number 2.47.650 and was registered in ClinicalTrials.

\section{Participants}

Subjects were randomized into two groups: intervention group [analgesia with LED therapy $(n=14)$ ] and control group [analgesia with shower therapy $(n=15)$ ].

Patients were admitted to the obstetric center after having been examined in the obstetrics emergency room and after the need for hospitalization for labor monitoring was confirmed. Normally, patients were hospitalized with cervical dilation around $4 \mathrm{~cm}$ and pain that was considered bearable. After being received at the obstetric center, accompanied by a person of their choice for the whole duration of labor, patients were approached by the research team, the purpose of the study was explained, and patients were asked whether they were interested in participating in the study. If so, they would sign a consent form.

Inclusion criteria. The study inclusion criteria were the following:

- Women who request analgesia during labor

- Multi-parous women

- Women with full-term pregnancies

- Women without previous illnesses, including diabetes or hypertension, neurological diseases, and metabolic diseases

- Women in whom fetal well-being could be assessed during analgesia.

\section{Exclusion criteria}

- Women who request pharmacological analgesia during childbirth

- Women submitted to previous cesarean sections and a recommendation for cesarean section at the time of admission, even if they were in labor.

\section{Procedures}

For the whole duration of labor, subjects in both groups were monitored, according to the recommendations of the WHO, both with regard to labor, by means of a partograph, as well as fetal well-being, using cardiotocography or intermittent auscultation of fetal heart rate. In addition, after birth, the health status of newborns was assessed using the Apgar score.

To analyze the effect of LED on analgesia during labor, the following variables were assessed: (1) perception of pain, (2) fetal well-being assessed by cardiotocography or intermittent auscultation, (3) Apgar score at minutes 1 and 5 after birth, and (4) labor duration. ${ }^{15}$

Pain perception was assessed by means of the visual analog scale (VAS) with scores and a continuous ruler varying from 0 to 10 , before and after the intervention. The scale had a size of $10 \mathrm{~cm}$, and patients were given an explanation that 10 meant the strongest pain they had ever felt and 0 meant absence of pain, and then they would point to a number on the scale that corresponded to the pain they were feeling at the time. The response of each subject was recorded with the aid of a millimeter ruler. 
Fetal well-being was assessed by cardiotocography or intermittent auscultation. During labor, baby's heart rate and the mother's uterine contractions were recorded electronically using a Doppler ultrasound transducer monitor.

Apgar score included color, heart rate, reflexes, muscle tone, and respiration to assess for signs of hemodynamic compromise, bradycardia, hypotonia, respiratory depression, or apnea. Each sign was scored 0 (zero), 1, or 2 in 5 parts and Apgar score can range from 0 to 10 . The score was recorded at 1 and $5 \mathrm{~min}$ in all infants and recording at 5-min intervals. Scores of 7-10 are considered reassuring.

In the intervention group, an LED plate was placed on the subjects' dorsal region at the level of T10 to S4, in contact with the skin. The procedure lasted $10 \mathrm{~min}$, with the plate automatically turning off. The plate used contains 72 light emitters, 36 in the red range $\left(660 \pm 20 \mathrm{~nm}, 5 \mathrm{~mW} / \mathrm{cm}^{2}, 3 \mathrm{~J}\right.$ per LED-108 J) and 36 in the infrared range $(850 \pm 20 \mathrm{~nm}$, $5 \mathrm{~mW} / \mathrm{cm}^{2}, 3 \mathrm{~J}$ per LED-108 J). The plate was $15 \times 25 \mathrm{~cm}$ and total radiant energy was 648 J (SPORTLUX-Cosmetical, Mauá, São Paulo, Brazil) (Table 1). LED was applied during labor when the following cervical dilation values were reached: 4-5, 6-7, and 8-9 $\mathrm{cm}$. At those three time points, the level of pain was assessed using a VAS in millimeters, before and shortly after the intervention. In the group in which shower was offered as a method of analgesia, the VAS was applied before and after the shower.

In the control group, subjects were referred to the shower when they reached cervical dilation above $6 \mathrm{~cm}$ and were offered the shower for about $30 \mathrm{~min}$, usually directing the flow of water to the dorsal region. Patients usually remain

\section{Table 1. Parameters of Photobiomodulation}

\begin{tabular}{|c|c|}
\hline Manufacturer & $\begin{array}{l}\text { Cosmedical (Mauá, } \\
\text { Sao Paulo, Brazil) }\end{array}$ \\
\hline Model identifier & Sportlux \\
\hline Year produced & 2017 \\
\hline $\begin{array}{l}\text { Number \& type of emitters } \\
\text { (laser or LED) }\end{array}$ & $\begin{array}{l}72 \text { LEDs ( } 36 \text { in red range } \\
\text { and } 36 \text { in the infrared } \\
\text { range) }\end{array}$ \\
\hline $\begin{array}{l}\text { Wavelength and bandwidth } \\
\text { (nm) }\end{array}$ & $\begin{array}{l}660 \pm 20 \text { and } \\
850 \pm 20 \mathrm{~nm}\end{array}$ \\
\hline $\begin{array}{l}\text { Pulse mode ( } \mathrm{CW} \text { or } \mathrm{Hz} \text {, duty } \\
\text { cycle) }\end{array}$ & $\mathrm{CW}$ \\
\hline Beam spot size at target $\left(\mathrm{cm}^{2}\right)$ & $1 \mathrm{~cm}^{2}$ \\
\hline Irradiance at target $\left(\mathrm{mW} / \mathrm{cm}^{2}\right)$ & $5 \mathrm{~mW} / \mathrm{cm}^{2}$ \\
\hline $\begin{array}{l}\text { If pulsed peak irradiance } \\
\left(\mathrm{mW} / \mathrm{cm}^{2}\right)\end{array}$ & - \\
\hline Exposure duration $(\mathrm{sec})$ & $600 \mathrm{sec}$ \\
\hline Radiant exposure $\left(\mathrm{J} / \mathrm{cm}^{2}\right)$ & $3 \mathrm{~J} / \mathrm{cm}^{2}$ \\
\hline Radiant energy $(\mathrm{J})$ & $\begin{array}{l}\text { Red: } 3 \mathrm{~J} \text { per } \mathrm{LED}=108 \mathrm{~J} \\
\text { Infrared: } 3 \mathrm{~J} \text { per } \\
\text { LED }=108 \mathrm{~J} \\
\text { Total }=216 \mathrm{~J}\end{array}$ \\
\hline Number of points irradiated & $\begin{array}{l}\text { Dorsal region at the level } \\
\text { of T10 to S4 }\end{array}$ \\
\hline Area irradiated $\left(\mathrm{cm}^{2}\right)$ & $72 \mathrm{~cm}^{2}$ \\
\hline Application technique & Contact \\
\hline $\begin{array}{l}\text { Number and frequency of } \\
\text { treatment sessions }\end{array}$ & $\begin{array}{l}\text { Three sessions during } \\
\text { labor }\end{array}$ \\
\hline $\begin{array}{l}\text { Total radiant energy over } \\
\text { entire treatment course }(\mathrm{J})\end{array}$ & $648 \mathrm{~J}$ \\
\hline
\end{tabular}

LED, light-emitting diode. seated in a chair, positioned under the shower, directing the flow of water to the dorsal region, but they are also free to direct the flow to other regions where analgesia is felt more deeply. The shower used in the researched institution is an ordinary shower.

As this is a controlled and randomized clinical trial, the provisions of CONSORT checklist were followed.

\section{Statistical analysis}

Data distribution was analyzed and continuous variables with normal data distribution were compared using $t$-test between groups and $t$-paired for before and after and expressed as mean \pm standard deviation. Categorical variables were analyzed using the chi-square test or Fisher's exact test. To analyze interaction between more than one variable, multivariate analysis was used. All analyzes were performed using SPSS statistical software, version 20.0, for Windows (IBM Corporation) at a significance level of $5 \%$.

\section{Results}

In this study, 29 women were enrolled; 14 of which were assigned to the experimental group and 15 to the control group. Table 2 describes sample characterization according to demographic data, number of pregnancies and parity.

\begin{tabular}{|c|c|c|}
\hline & $\begin{array}{c}G 1-L E D \\
(\mathrm{n}=14)\end{array}$ & $\begin{array}{l}\text { G2-Shower } \\
(\mathrm{n}=15)\end{array}$ \\
\hline \multicolumn{3}{|l|}{ Age } \\
\hline Mean (SD) & $\begin{array}{c}27.57(1.59) \\
\text { years old }\end{array}$ & $\begin{array}{c}22.33(1.29) \\
\text { years old }\end{array}$ \\
\hline Minimum-maximum & $\begin{array}{c}16-36 \\
\text { years old }\end{array}$ & $\begin{array}{c}14-31 \text { years } \\
\text { old }\end{array}$ \\
\hline \multicolumn{3}{|l|}{ Income, $n(\%)$} \\
\hline Less than 1 minimum wage & $1(33.3 \%)$ & $2(66.7 \%)$ \\
\hline 1 minimum wage & $1(100 \%)$ & 0 \\
\hline 2 to 3 minimum wages & $11(50 \%)$ & $11(50 \%)$ \\
\hline 3 to 4 minimum wages & 0 & $2(100 \%)$ \\
\hline Over 4 minimum wages & $1(100 \%)$ & 0 \\
\hline \multicolumn{3}{|l|}{ Marital status, $n(\%)$} \\
\hline Married & $5(50 \%)$ & $5(50 \%)$ \\
\hline Single & $4(36.4 \%)$ & $7(63.6 \%)$ \\
\hline Consensual union & $5(62.5 \%)$ & $3(37.5 \%)$ \\
\hline \multicolumn{3}{|l|}{ Academic background, $n(\%)$} \\
\hline High school & 0 & $1(100 \%)$ \\
\hline Middle school & $2(33.3 \%)$ & $4(66.7 \%)$ \\
\hline Incomplete high school & $2(28.6 \%)$ & $5(71.4 \%)$ \\
\hline Completed high school & $9(69.2 \%)$ & $4(30.8 \%)$ \\
\hline Higher education & $1(50 \%)$ & $1(50 \%)$ \\
\hline \multicolumn{3}{|l|}{ Pregnancies, $n(\%)$} \\
\hline 1 & $5(27.8 \%)$ & $13(72.2 \%)$ \\
\hline 2 & $6(85.7 \%)$ & $1(14.3 \%)$ \\
\hline 3 & $2(66.7 \%)$ & $1(33.3 \%)$ \\
\hline 4 & $1(100 \%)$ & 0 \\
\hline \multicolumn{3}{|l|}{ Parity, $n(\%)$} \\
\hline 0 & $5(29.4 \%)$ & $12(70.6 \%)$ \\
\hline 1 & $6(85.7 \%)$ & $1(14.3 \%)$ \\
\hline 2 & $3(60 \%)$ & $2(40 \%)$ \\
\hline
\end{tabular}

SD, standard deviation. 
Table 3. Comparison of Pain Report Means Before AND AfTER InTERVENTION IN EACH Group (INTRAGROUP) - PAIRED $T$-TEST

\begin{tabular}{llcccc}
\hline & VAS & Mean & $\mathrm{n}$ & SD & $\mathrm{p}$ \\
\hline G1-LED & Before & 9.274 & 14 & 0.8810 & $0.011^{*}$ \\
& After & 7.952 & 14 & 1.7860 & \\
G2-Shower & Before & 9.533 & 15 & 0.8338 & 0.189 \\
& After & 8.933 & 15 & 1.2799 & \\
\hline
\end{tabular}

*Statistically significant, $p<0.05$.

VAS, visual analog scale.

Mean age by group was 27.57 (1.59) in the group that used the LED plate and 22.33 (1.29) in the shower group. It is observed that the average income in both groups was lesser than three minimum wages. Most of the subjects were single or in a consensual union. In the shower group, $72.2 \%$ ( $n=13$ ) were pregnant for the first time, whereas in the LED group $27.8 \%(n=5)$, as shown in Table 2 .

When analyzing pain using the millimetric visual scale, reduced pain was observed in both groups. However, in group G1 (LED group), this reduction was greater with a statistically significant difference. The average pain level in G1 decreased by $14.25 \%$ (mean initial $\mathrm{VAS}=9.274$; final mean $\mathrm{VAS}=7.952$ ), whereas in $\mathrm{G} 2$ it decreased $6.29 \%$ (initial mean $\mathrm{VAS}=9.533$; final mean VAS $=8.933$ ) (Table 3 and Fig. 1).

The average birth weight at the LED group was $3195.571 \mathrm{~g}$ and that of the shower group was $3399.000 \mathrm{~g}$, with no statistically significant difference in birth weights between the groups (Table 4).

The Apgar score at birth for both groups was $>7$, demonstrating that the LED plate did not lead to changes in newborns' birth conditions (Table 5). The same was observed for fetal well-being monitoring during labor, in which intermittent auscultation of fetal heart rate and cardiotocography were used.

The use of oxytocin, a hormone used during labor to correct the pattern of uterine contractions, was also similar between both groups, demonstrating that the use of the LED plate in the study group did not change the pattern of uterine contractions, and did not negatively affect labor evolution (Table 6)

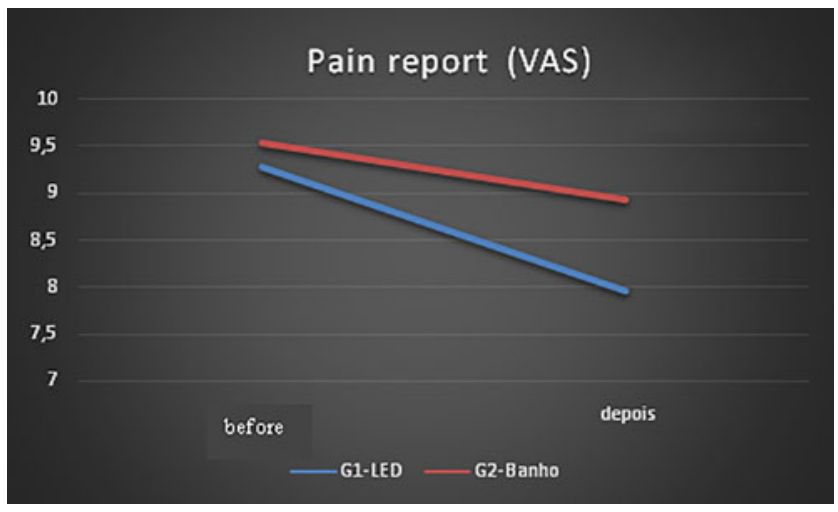

FIG. 1. Graphical representation of pain report (VAS) in both groups before and after interventions. VAS, visual analog scale.
Table 4. Comparative Analysis of Weight AT BirTh In Both Groups

\begin{tabular}{|c|c|c|c|c|c|c|}
\hline & \multirow[b]{2}{*}{$\mathrm{n}$} & \multirow{2}{*}{$\begin{array}{l}\text { Weight at } \\
\text { birth (kg) }\end{array}$} & \multirow[b]{2}{*}{$S D$} & \multicolumn{2}{|c|}{$\begin{array}{c}\text { Confidence } \\
\text { interval (95\%) }\end{array}$} & \multirow[b]{2}{*}{$\mathrm{p}$} \\
\hline & & & & Lower & Upper & \\
\hline G1-LED & 14 & 3195.571 & 387.263 & -488.16 & 81.30 & 0.52 \\
\hline G2-Shower & 15 & 3399.000 & 360.110 & -489.18 & 82.32 & \\
\hline
\end{tabular}

Regarding the status of amniotic membranes, there was also no statistically significant difference between the two groups (Table 7). Membrane rupture is often used to correct the pattern of uterine contractions.

A multi-variate analysis of the interaction between the use of oxytocin, study group, and pain demonstrated that there was a statistically significant difference in relation to pain, but there was no difference regarding the use of oxytocin (Table 8). There was no statistically significant difference between the two groups of labor duration in hours (Table 9).

Considering that the number of subjects selected for this study was lesser than the sample initially proposed, the power of the sample was calculated using a post hoc sample calculation in GPower 3.1 program (Kiel University, Germany), considering the difference in mean pain intensity before and after interventions. A 93\% power and effect magnitude of 1.15 was observed (Fig. 2).

\section{Discussion}

\section{Principal findings}

The results of our clinical trial showed that LED was safe and effective as a nonpharmacological alternative to control pain during labor. We observed differences in decreased level of labor pain between LED group and shower group.

Our findings demonstrate that the LED plate did not lead to changes in newborns' birth conditions. There was no difference in Apgar. LED did not change the pattern of uterine contractions and did not negatively affect labor evolution. Photobiomodulation did not change labor duration.

\section{Results in context}

Pain experienced during labor, often characterized as unbearable, leads many women to choose a cesarean delivery, often encouraged by the health care professional seeing them during labor. Brazil is facing an epidemic of cesarean deliveries, of $\sim 50 \%$ of births, whereas a $15 \%$ rate is recommended by the WHO. The lack of analgesia options during labor is

Table 5. Analysis of Apgar Scores 1 And 5 Min After Birth, According to the Groups Studied

\begin{tabular}{|c|c|c|c|c|c|c|c|}
\hline & \multirow{2}{*}{$\begin{array}{c}\text { Apgar } \\
\text { (min) }\end{array}$} & \multirow[b]{2}{*}{ Mean } & \multirow[b]{2}{*}{$\mathrm{n}$} & \multirow[b]{2}{*}{$S D$} & \multirow[b]{2}{*}{$\mathrm{p}$} & \multicolumn{2}{|c|}{$\begin{array}{c}\text { Confidence } \\
\text { interval (95\%) }\end{array}$} \\
\hline & & & & & & Lower & Upper \\
\hline \multirow[t]{2}{*}{ G1-LED } & 1 & 8.50 & 14 & 1.345 & 0.070 & -1.188 & 0.321 \\
\hline & 5 & 8.93 & 14 & 0.458 & & -1.236 & 0.369 \\
\hline \multirow[t]{2}{*}{ G2-Shower } & 1 & 9.64 & 15 & 0.633 & 0.100 & -0.562 & 0.248 \\
\hline & 5 & 9.80 & 15 & 0.414 & & -0.572 & 0.258 \\
\hline
\end{tabular}


TABLE 6. Use OF OXYTOCIN, ACCORding to the Number of SubJects and Group

\begin{tabular}{lccrc}
\hline & \multicolumn{2}{c}{ Group } & & \\
\cline { 2 - 3 } Oxytocin & G1-LED & G2-Shower & Total & $\mathrm{p}$ \\
\hline No $(n)$ & 6 & 5 & 11 & 0.442 \\
$\%$ & $54.5 \%$ & $45.5 \%$ & $100 \%$ & \\
Yes $(n)$ & 8 & 10 & 18 & \\
$\%$ & $44.4 \%$ & $55.6 \%$ & $100 \%$ & \\
\hline
\end{tabular}

pointed out as one of the reasons mentioned by patients for choosing cesarean section as the type of delivery. ${ }^{16}$ Aspects related to postpartum complications, unfortunately, are often not considered when choosing the type of delivery. Cesarean delivery has been associated with increased risk of postpartum infection, urinary tract infection, headache, pain, and complications from anesthesia; and, differently from what was expected, it was not a protective factor against late complications, such as urinary and fecal incontinence, cystocele, and uterus prolapse. ${ }^{17}$

A review carried out by Thomson et al. ${ }^{21}$ comparing women who used pharmacological and nonpharmacological analgesia methods demonstrated that, although pharmacological methods are more effective in reducing pain, they are not associated with better patient satisfaction during labor. ${ }^{18}$ Therefore, labor satisfaction is not only associated with reduced pain, but also with other factors, such as greater control over the physiological aspects related to birth. ${ }^{19}$ Another research carried out by Lindholm and Hildingsson correlating several methods of analgesia during labor, including shower and epidural anesthesia, again observed that although women experienced a more significant reduction in pain with epidural anesthesia, this did not translate into satisfaction at delivery. ${ }^{20}$ This reinforces that LED plates, by giving patients the opportunity to choose the most comfortable position for them, while acting as the main agents of the birth process, provide, in addition to analgesia, greater satisfaction in such an important moment of a woman's life. In addition, LED plates proved to be easy to use and its application did not lead to patient discomfort.

Another important aspect regarding the use of pharmacological methods for labor analgesia is that they have been associated with the need to use forceps or vacuum as an aid during the expulsion stage, which is more frequently related to mechanical and psychological trauma of patients. ${ }^{21}$

Table 7. Sample Distribution, According to the Characteristic of Amniotic Membranes AND THE GROUP STUDIED

\begin{tabular}{lccrc}
\hline & \multicolumn{2}{c}{ Group } & & \\
\cline { 2 - 3 } & G1-LED & G2-Shower & Total & $\mathrm{p}$ \\
\hline $\begin{array}{l}\text { Not ruptured }(n) \\
\text { Membranes }\end{array}$ & 8 & 6 & 14 & 0.291 \\
$\quad \begin{array}{l}\text { Amniotic } \\
\quad \text { Ruptured }(n)\end{array}$ & $57.1 \%$ & $42.9 \%$ & $100 \%$ & \\
$\%$ & $60.0 \%$ & $60.0 \%$ & $100 \%$ & \\
\hline
\end{tabular}

Table 8. Multi-Variate Analysis OF THE INTERACTION BETWEEN OXYTOCIN Use, Study Group, and Pain

\begin{tabular}{lrrrc}
\hline & Value & \multicolumn{1}{c}{$F$} & Sig. & $\begin{array}{c}\text { Observed } \\
\text { power }\end{array}$ \\
\hline Pain & 0.664 & 49.484 & 0.000 & 1.000 \\
Pain $\times$ group & 0.094 & 2.602 & 0.119 & 0.342 \\
Pain $\times$ oxytocin & 0.119 & 3.388 & 0.078 & 0.425 \\
Pain $\times$ group $\times$ oxytocin & 0.140 & 4.075 & 0.054 & 0.492 \\
\hline
\end{tabular}

Subjects who participated in the study and were assigned to the LED group were mainly pregnant for the second time, whereas in the shower group, the majority was pregnant for the first time. There is a difference between the pain reported by patients according to parity, especially at the beginning of labor, but during labor, pain starts to be quantified in a similar way regardless of patient's parity. ${ }^{22}$

In general, we observed that nonpharmacological methods, as they are unable to cross the placental barrier, do not lead to changes in fetal well-being. A study carried out by Santana et al., using transcutaneous stimulation, demonstrated that there was no change in relation to Apgar scores and duration of labor. ${ }^{23}$ The same was observed with the use of LED plates, which did not lead to changes in fetal well-being during labor, and also in Apgar scores at birth, demonstrating that there was no interference in fetal well-being during labor.

Increased use of oxytocin and ruptured amniotic membranes, methods used to improve the pattern of uterine contraction, ${ }^{24}$ and which can also cause increased pain during labor, were also not observed. This makes us infer that the use of the plate did not interfere in the uterine contraction pattern and, therefore, in labor evolution.

Although pharmacological options are currently considered the most effective method of analgesia during labor, these have been more frequently associated with higher incidence of side effects and instrument-assisted deliveries. ${ }^{25}$ In addition, it requires specialized professionals to be constantly present during labor, which is often not feasible in public hospitals and also in many private hospitals.

\section{Clinical and research implications}

This study presented an evaluation of the effect of LED therapy on analgesia during labor. The clinical potential of using LED therapy for pain control during labor involves the ease application, the possibility of application by the same professional team that supports the woman during labor, the option of the patient selects the best position and enhanced mobility. The major implication of this research was to show of an analgesic alternative intervention during labor that is effective and available for use in public and private services. Our findings may help develop protocols research using photobiomodulation.

Table 9. Comparison of Labor Duration in Hours In THE Groups STUdied

\begin{tabular}{llccc}
\hline & Group & Mean & SD & $\mathrm{p}$ \\
\hline Labor duration & G1-LED & 4.21 & 1.251 & 0.377 \\
& G2-Shower & 4.77 & 1.954 & \\
\hline
\end{tabular}




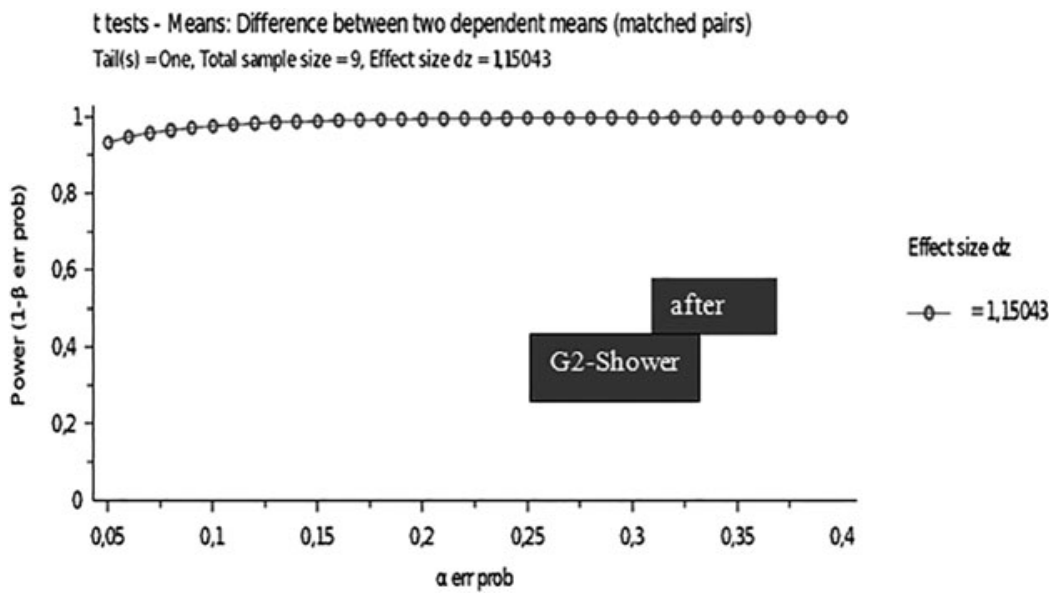

FIG. 2. Graphical representation of power of the sample calculated using a post hoc sample calculation in GPower 3.1 program (Kiel University, Germany).

\section{Strength and limitations}

This is the first study in the literature that used infrared LED for analgesia during labor. It presents an innovative and affordable technique that can be widely used in obstetric centers, including both public and private institutions. Our results show that LED plates seem to be an effective alternative for labor analgesia. Showers also help reduce pain, but not as effectively as LED plates. The use of showers, as a method of reducing pain, can often not be offered to women when they need it, as many institutions do not have bathrooms with showers in sufficient amount for several patients to use at the same time.

The limitations of this study include that it was performed comparing just one nonpharmacological method, hot shower. This limitation did not permit to know if photobiomodulation is more effective than other techniques and we did not have a control group treated with a pharmacological analgesia.

\section{Conclusions}

It was concluded that photobiomodulation with LED provided greater analgesic effect during labor, in comparison with that offered by a hot shower in the group studied. The technique was also shown to be safe in terms of fetal and parturient well-being.

\section{Authors' Contributions}

Conceptualization, methodology, investigation, resources, and writing-original draft by M.A.T. and A.C.R.T.H. Writing-review and editing, visualization, and supervision by A.P.T.S. Writing-review and editing, visualization, supervision, and project administration by K.P.S.F. Software, validation, formal analysis, and data curation by D.d.F.T.S. and C.P. Software, validation, formal analysis, investigation, resources, and data curation by R.A.M.-F. Review and editing, and visualization by A.O.G. Conceptualization, methodology, writing - review and editing, visualization, supervision, and project administration by S.K.B. Conceptualization, methodology, software, validation, formal analysis, investigation, resources, data curation, writingoriginal draft, review, and editing, visualization, supervision, project administration, and funding acquisition by L.J.M.

\section{Author Disclosure Statement}

No competing financial interests exist.

\section{Funding Information}

No funding was received for this study.

\section{References}

1. Keag OE, Norman JE, Stock SJ. Long-term risks and benefits associated with cesarean delivery for mother, baby, and subsequent pregnancies: systematic review and metaanalysis. PLoS Med 2018;15:e1002494.

2. Kristensen K, Henriksen L. Cesarean section and disease associated with immune function. J Allergy Clin Immunol 2016;137:587-590.

3. Mylonas I, Friese K. Indications for and risks of elective cesarean section. Dtsch Arztebl Int 2015;112:489-495.

4. Gama ADS, Giffin KM, Angulo-Tuesta A, Barbosa GP, d'Orsi E. Women's representations and experiences with vaginal and cesarean delivery in public and private maternity hospitals. Cad Saúde Pública 2009;25:2480-2488.

5. Jones L, Othman M, Dowswell T, et al. Pain management for women in labour: an overview of systematic reviews. Cochrane Database Syst Rev 2012;2012:CD009234.

6. Mei-Yueh C, Chung-Hey C, Huang C. A comparison of massage effects on labor pain using the McGill Pain Questionnaire. J Nurs Res 2006;14:190-197.

7. Lee H, Ernst E. Acupuncture for labor pain management: a systematic review. Am J Obstet Gynecol 2004;191:15731579.

8. Davim RMB, de Vasconcelos Torres G, da Costa Dantas J, et al. Banho de chuveiro como estratégia não farmacológica no alívio da dor de parturientes. Rev Eletr Enferm 2008;10: 600-609.

9. Beebe KR. Hypnotherapy for labor and birth. Nurs Womens Health 2014;18:48-59.

10. Madden K, Middleton P, Cyna AM, Matthewson M, Jones L. Hypnosis for pain management during labour and childbirth. Cochrane Database Syst Rev 2012;11:CD009356.

11. Kim WS, Calderhead RG. Is light-emitting diode phototherapy (LED-LLLT) really effective? Laser Ther 2011;20: 205-215.

12. Tantawy SA, Abdelbasset WK, Kamel DM, Alrawaili SM, Alsubaie SF. Laser photobiomodulation is more effective 
than ultrasound therapy in patients with chronic nonspecific low back pain: a comparative study. Lasers Med Sci 2019; 34:793-800.

13. Huang Z, Ma J, Chen J, Shen B, Pei F, Kraus VB. The effectiveness of low-level laser therapy for nonspecific chronic low back pain: a systematic review and meta-analysis. Arthritis Res Ther 2015;17:360.

14. Koldaş Doğan Ş, Ay S, Evcik D. The effects of two different low level laser therapies in the treatment of patients with chronic low back pain: a double-blinded randomized clinical trial. J Back Musculoskelet Rehabil 2017;30:235240.

15. Traverzim MADS, Makabe S, Silva DFT, et al. Effect of led photobiomodulation on analgesia during labor: study protocol for a randomized clinical trial. Medicine (Baltimore) 2018;97:e11120.

16. Riscado LC, Jannotti CB, Barbosa RHS. Decisão pela via de parto no brasil: temas e tendências na produção da saúde coletiva. Texto Contexto Enferm 2016;25:e3570014.

17. Mascarello KC, Matijasevich A, Santos IDSD, Silveira MF. Complicações puerperais precoces e tardias associadas à via de parto em uma coorte no Brasil. Ver Bras Epidemiol 2018;21:e180010.

18. Mamede FV, Almeida AM, Souza L, Mamede ML. A dor durante o trabalho de parto: o efeito da deambulação. Rev Lat Am Enfermagem 2007;15:1157-1162.

19. Rossen J, Østborg TB, Lindtjørn E, Schulz J, Eggebø TM. Judicious use of oxytocin augmentation for the management of prolonged labor. Acta Obstet Gynecol Scand 2016; 95:355-361.

20. Smith LA, Burns E, Cuthbert A. Parenteral opioids for maternal pain management in labour. Cochrane Database Syst Rev 2018;6:CD007396.

21. Thomson G, Feeley C, Moran VH, Downe S, Oladapo OT. Women's experiences of pharmacological and non- pharmacological pain relief methods for labour and childbirth: a qualitative systematic review. Reprod Health 2019; $16: 71$.

22. Beigi NM, Broumandfar K, Bahadoran P, Abedi HA. Women's experience of pain during childbirth. Iran J Nurs Midwifery Res 2010;15:77-82.

23. Santana LS, Gallo RB, Ferreira CH, Duarte G, Quintana SM, Marcolin AC. Transcutaneous electrical nerve stimulation (TENS) reduces pain and postpones the need for pharmacological analgesia during labour: a randomised trial. J Physiother 2016;62:29-34.

24. Hidalgo-Lopezosa P, Hidalgo-Maestre M, Rodríguez-Borrego MA. Labor stimulation with oxytocin: effects on obstetrical and neonatal outcomes. Rev Lat Am Enfermagem 2016;24: e2744.

25. Anim-Somuah M, Smyth RM, Cyna AM, Cuthbert A. Epidural versus non-epidural or no analgesia for pain management in labour. Cochrane Database Syst Rev 2018; 5:CD000331.

Address correspondence to: Sandra Kalil Bussadori, PhD Biophotonics Applied to Health Sciences University Nove de Julho Vergueiro Street, 235/249-Liberdade São Paulo 01504-001 São Paulo Brazil

E-mail: sandra.skb@gmail.com

Received: October 29, 2020. Accepted after revision: December 17, 2020. Published online: March 23, 2021. 